\title{
AN ABERRANT NEW GENUS OF MYRMICINE ANT FROM MADAGASCAR ${ }^{1}$
}

\author{
BY WILLIAM L. BROWN, JR. \\ Department of Entomology \\ Cornell University \\ Ithaca, New York 14853
}

\begin{abstract}
During a research trip to the Old World tropics during January to April 1977, I was allowed by M. A. Peyrieras, of the Institut de Recherche Scientifique of the Malagasy Republic in Tananarive, to sort through some berlesates of humus and leaf litter collected by him in various parts of Madagascar. Among these samples, I discovered a single worker example of an extraordinary new genus and species of Myrmicinae. M. Peyrieras has my thanks for these and many other interesting samples, including several undescribed species of ants. Among these are the first recorded representatives of Discothyrea and Amblyopone found on Madagascar, to be described in a separate publication. The new genus is described next below.
\end{abstract}

\section{Pilotrochus new genus}

Worker: Subfamily Myrmicinae, tribe unknown. Integument thick and rigid. Head subpyriform, slightly depressed but convex, broadest behind, without posteromedian excision; frontal carinae far apart, at sides of head, produced laterad angularly above antennal insertions, continuous posteriad with the sharp upper margins of deep and broad antennal scrobes occupying about $2 / 3$ of length of sides of head; eyes small, situated on ventral borders of scrobes near their posterior ends, slightly posterior to midlength of head. Antennae 8-merous, scapes short and thick, much narrowed basad; club distinctly 2-merous, slightly longer than remainder of funiculus, apical segment about twice as long as

\footnotetext{
${ }^{1}$ Hymenoptera: Formicidae. A report of research from the Cornell University Agricultural Experiment Station. Research supported by National Science Foundation Grant DEB 75-22427.

Manuscript received by the editor February 3, 1978.
} 
penultimate; funicular (ring) segments II-V small, subequal in length, broader than long; funicular segment I (pedicel) about equal in length to the next 2 to 3 (ring) segments.

Clypeus broad, shield-shaped, narrowed sharply laterad on each side, its surface gently convex; anterior margin broadly arcuate, with a complex median notch.

Mandibles triangular, convex, with opposable, serially-toothed mesial margins (teeth coarse, sharp, 7 in number on each mandible); these margins arcuate in side view and finally directed ventrad at apex. In the vee between each of the larger teeth is a minute piligerous denticle. Labrum thick, linguiform and narrowly rounded at apex, but appearing truncate in side view; its dorsal surface bearing a narrow pencil of fine white setae that arches forward to extend beyond the mandibular apices, probably serving as a "rangefinder" trigger hair. Palpi not visible and undoubtedly short, but segmentation not determined.

Trunk compact, its dorsal outline forming one continuous arc from base of pronotal cervix to petiolar insertion, dominated by pronotum. which makes up about half its length and is wider than the rest (a little more than half as wide as head). Promesonotal suture marked by a faint curved transverse line paralleled by a costa on the dorsum, but completely fused here, though complete on the pleura. Pronotum with blunt, barely suggested humeral angles as seen from above, but not distinctly marginate in front or on the sides; upper sides bulging and overhanging lower sides; ventral margins each forming a curved, cultrate, projecting flange or lamella. Metanotal groove obsolete, its position perhaps marked by a transverse carina at the top of what appears to be the propodeal declivity, but the true declivity probably is confined to the lower part of this slope, beneath a lower and weaker transverse carina or costula.

Mesopleura narrow and impressed, but their lower central parts (mesepisterna) are occupied on each side by a peculiar organ consisting of a large subcircular pit filled with a silvery-white, convex pad of fine, radially-arranged hairs. The anterior edge of this structure forms the posterior side of the ventral invagination between pro- and mesonotum, but a broad piece of mesokatepisternal cuticle separates the organ from the mesocoxa. This organ appears to be the external part of an exocrine gland or glands, though the gland openings, if any, are hidden by the pad of fine hairs. 
The (probably) true propodeal declivity small, flat, steep, unarmed, bounded by an inverted U-shaped carina, flanked on each side by the large, circular openings of the propodeal spiracles, which are directed caudad. Inferior propodeal plates low and rounded.

Petiole curved-clavate, with a long, subcylindrical anterior peduncle, a long, low, rounded node, and poorly-defined posterior peduncle, or collar. Postpetiole rounded above and on the sides, broader behind than in front, and about as broad as long; sternum boxlike, with inwardly sloping sides and a flat, subrectangular ventral face limited on all 4 sides by sharp carinae; broadly attached to gaster behind, but with a moderate constriction between the 2 tagmata.

Gaster rounded at base to the basal constriction, which has a few short longitudinal costulae hidden within it. Basal segment extending over about $2 / 3$ length of gaster, the remaining 3 visible segments curving to a pointed apex; terminal external (seventh) sternite (hypopygium) acutely pointed; sting with acute tip exserted, some of the rest of the shaft visible through transparent cuticle.

Legs moderately long. Femur robust, its flexor surface sulcate apicad to receive the folded tibia; tibia claviform, thickest near apical third, lacking spurs on middle and hind legs; tarsus slender, cylindrical; claws small, slender, simple.

Sculpture mostly shining; head both above and below (except clypeus and antennal scrobes) covered with a coarse reticulum of costulae forming large, shallow-polygonal fossae, each of which bears a long, fine, curved hair arising from an inconspicuous puncture, usually near the margin of the fossa. Similar sculpture on truncal dorsum, though here 10-11 longitudinal costae predominate. A broad median strip is nearly smooth, forming a very shallow median sulcus, which has a modest costa or carina in the middle. (The median posterior vertex is feebly subsulcate in much the same way.) Propodeum (sloping dorsum and declivity) nearly or quite smooth. Sides of trunk smooth and shining, but the posterior half with 5 strong costae radiating outward from the mesopleural organ. Petiolar and postpetiolar nodes loosely longitudinally rugose, with broad, shining interspaces; peduncles and sides of these segments becoming finely and densely punctate-reticulate and more opaque; ventral rectangle of postpetiole smooth and shining. Gaster smooth and shining, except posterolateral margins 
of segments, which are delicately reticulate-striolate, but still shining. Mandibles densely and finely punctulate, opaque (teeth infuscate and shining), lateral surfaces finely longitudinally costulate basad. Antennal scapes and legs shining, finely longitudinally rugulose to smooth; antennal funiculi densely punctulate, pubescent and opaque. Antennal scrobes basically smooth and shining, but each is crossed by 7-9 vermiculate transverse rugulae.

Pilosity consisting of long, fine, flexuous erect to decumbent hairs distributed widely over dorsal surfaces of body, and on scapes and legs, sparser on underside of head and gaster. Mandibles, antennal funiculi, and flexor surfaces of tibiae and tarsi with fine, appressed to decumbent pubescence.

Color light ferruginous red; antennae and legs more yellowish.

Queen, male and larva still unknown.

Type species: Pilotrochus besmerus, new species, described below. Distribution as far as known limited to Madagascar.

Pilotrochus besmerus new species

Figs. 1, 2 .

Holotype worker: Total length (TL) 2.9, head length (HL) 0.68 , head width (HW) 0.60 , mandibles extend beyond median clypeal free margin (ML) $0.11 \mathrm{~mm}$; when head is tilted back a little from full-face view, mandibles may extend beyond clypeus as much as $0.18 \mathrm{~mm}$; trunk length (WL) 0.64 , scape $\mathrm{L}$ (excluding radicle) 0.32 , greatest length of eye $0.07 \mathrm{~mm}$. Petiole length (chord of arc) 0.45 , hind femur length 0.43 , hind tibia length 0.34 , hind tarsus length $0.60 \mathrm{~mm}$, of which metatarsus is half.

Details of form and sculpture are well shown in the figures. As seen in dorsal view, eyes hidden in full-face view, barely visible when head is tilted back slightly, as in fig. 1. Pronotum slightly broader than long (width $0.38 \mathrm{~mm}$ ), rounded in front, excised behind; mesonotum subquadratic, about $0.20 \mathrm{~mm}$ wide, with feebly convex borders on all four sides. Petiolar node $0.17 \mathrm{~mm}$ wide, postpetiolar node with rounded sides, slightly wider behind (width $0.21 \mathrm{~mm}$, length $0.20 \mathrm{~mm}$ ).

Pronotum smooth and shining, with about 10 costulae running longitudinally at different lengths; mesonotum with 5 longitudinal costulae on rugulae. About 5 longitudinal rugules each on petiolar and postpetiolar nodes, but weaker on the postpetiole, so that its disc is primarily smooth and shining like the gaster. 


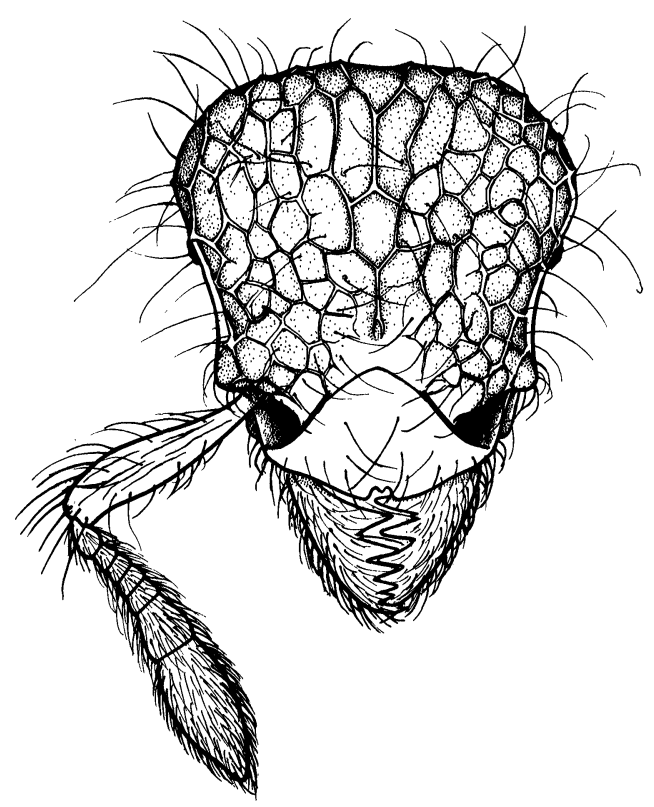

Fig. 1, Pilotrochus besmerus, new genus and species, holotype worker, head in dorsal view, tilted back slightly from the full-face position so as to show the mandibular dentition better, $\times 67$. Drawing by Susan Poulakis.

Hairs mostly a little less than $0.1 \mathrm{~mm}$ long on anterior head and scapes, a little more than $0.1 \mathrm{~mm}$ on posterior vertex; $0.15-0.25$ on trunk, petiole, postpetiole and gaster, becoming shorter again at gastric apex; about 0.1 to about $0.3 \mathrm{~mm}$ on legs; flagelliform, many with tips reflexed or even looped back.

Holotype (Museum of Comparative Zoology at Harvard University) a unique worker taken in a Berlese sample of forest humus and litter from along the road to Anosibé, $33 \mathrm{~km}$ south of Moramanga, in east central Madagascar, 4-12 April 1975 (A. Peyrieras).

The relationships of Pilotrochus are obscure. The shape of the head, with its broad and deep scrobes and small ventrolateral eyes, recalls that of Dacetinops, or the Codiomyrmex group of Dacetini, or even Tatuidris, but Pilotrochus differs strongly from all of these in its 8-segmented antennae, in the form of its mandibles and their teeth, and in the form of its trunk and petiole. The lateral "hair- 


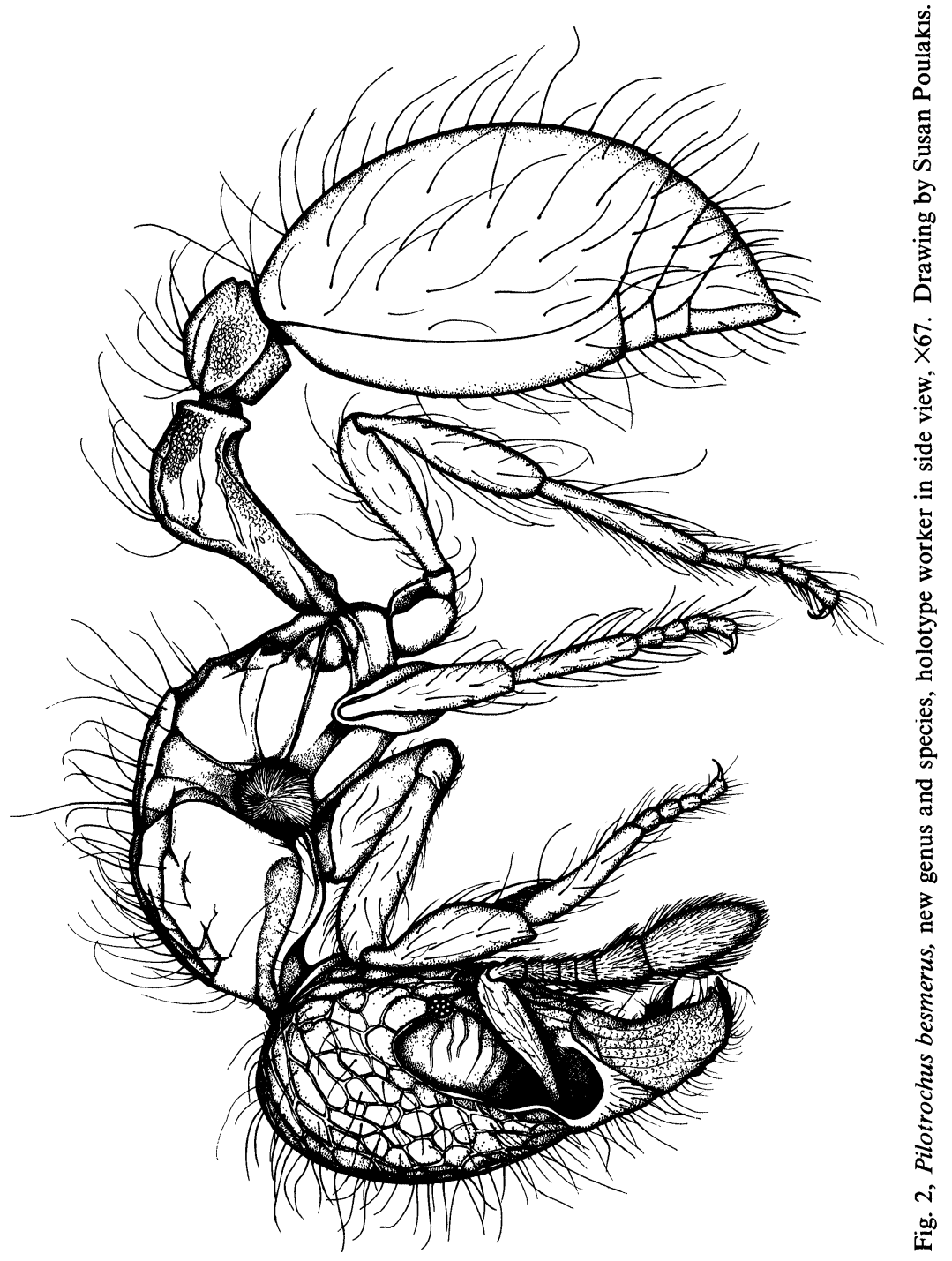


wheel" organs are also striking, and so far as I am aware are unmatched among the ants, although the region of the ventral furrow between pro- and mesothorax is sometimes modified and apparently glandular in some dacetines and a few other myrmicines.

The 2-segmented antennal club, together with some points of habitus (especially coarse sculpture and long, flexuous pilosity, plus the antennal scrobes), recalls the neotropical genus Lachnomyrmex, but the shape of the trunk in Pilotrochus is completely different, the propodeal teeth so prominent in Lachnomyrmex are completely absent, and the mandibles in the two genera are very different.

At the moment, all one can say without seeing the winged forms and larvae of Pilotrochus, and without knowing something of its lifeway, is that it is a member of subfamily Myrmicinae, but one not belonging to any of the well-circumscribed "higher" tribes (Crematogastrini, Dacetini, Basicerotini, Cataulacini, Attini, etc.). Thus, it falls among the mass of generic complexes related to Myrmica, Pheidole, Myrmecina, Rogeria, etc., among which tribal boundaries are impossible to define for the present, or at least are in dispute.

Considering the revisionary work that must be done before we have a rational tribal classification of Myrmicinae, it seems to me that nothing would be gained by erecting a new tribe for Pilotrochus, even though for the time being I am able to fit it comfortably into any existing myrmicine tribe.

The generic name is derived from the Greek 'pilos' (hair) + 'trochos' (wheel), while the specific name besmerus combines the Latin 'bes' (eight of twelve) with the Greek 'meros' (part), in reference to the 8-segmented antennae as compared to the primitive myrmicine (and formicid) 12-merous condition. 

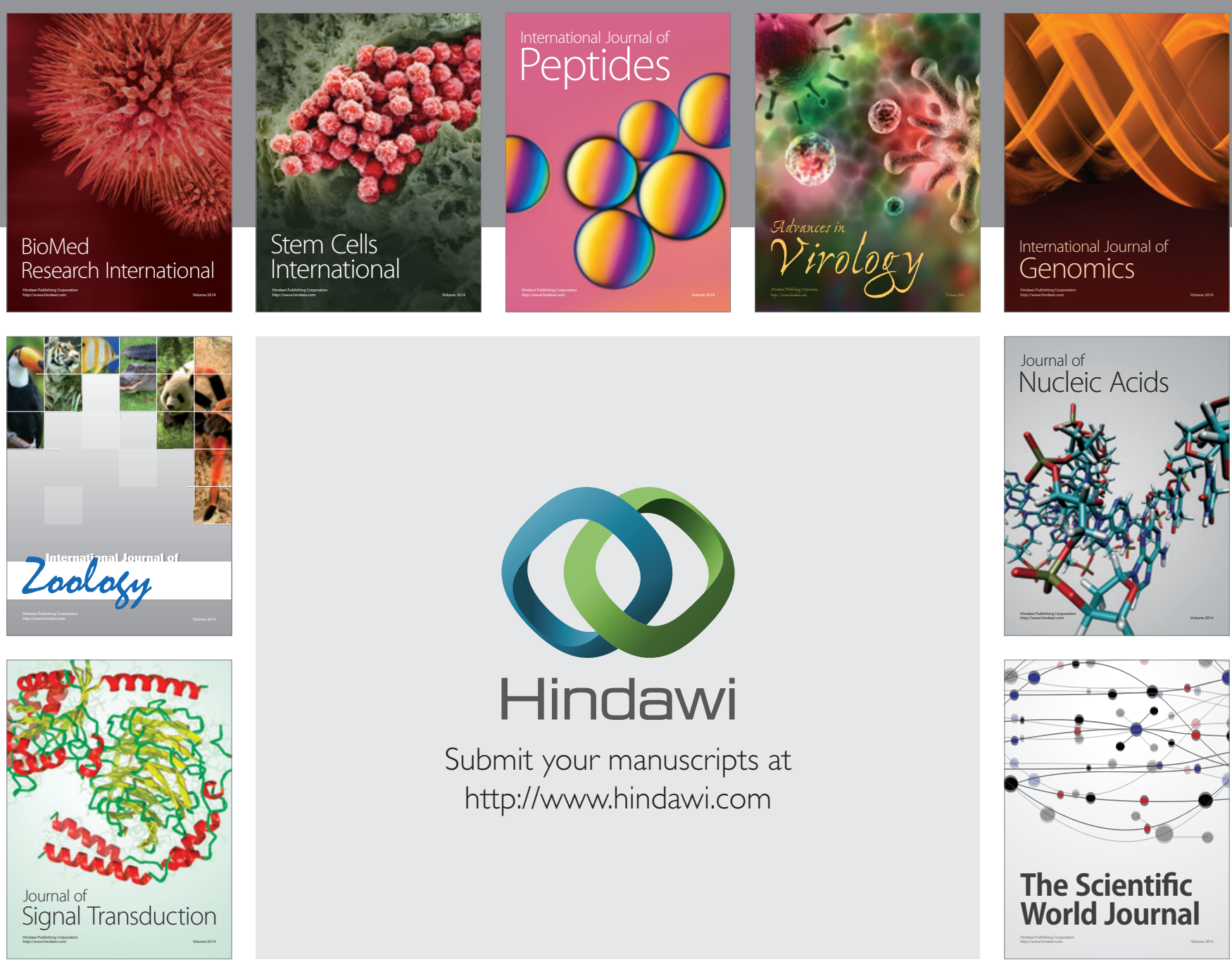

Submit your manuscripts at

http://www.hindawi.com
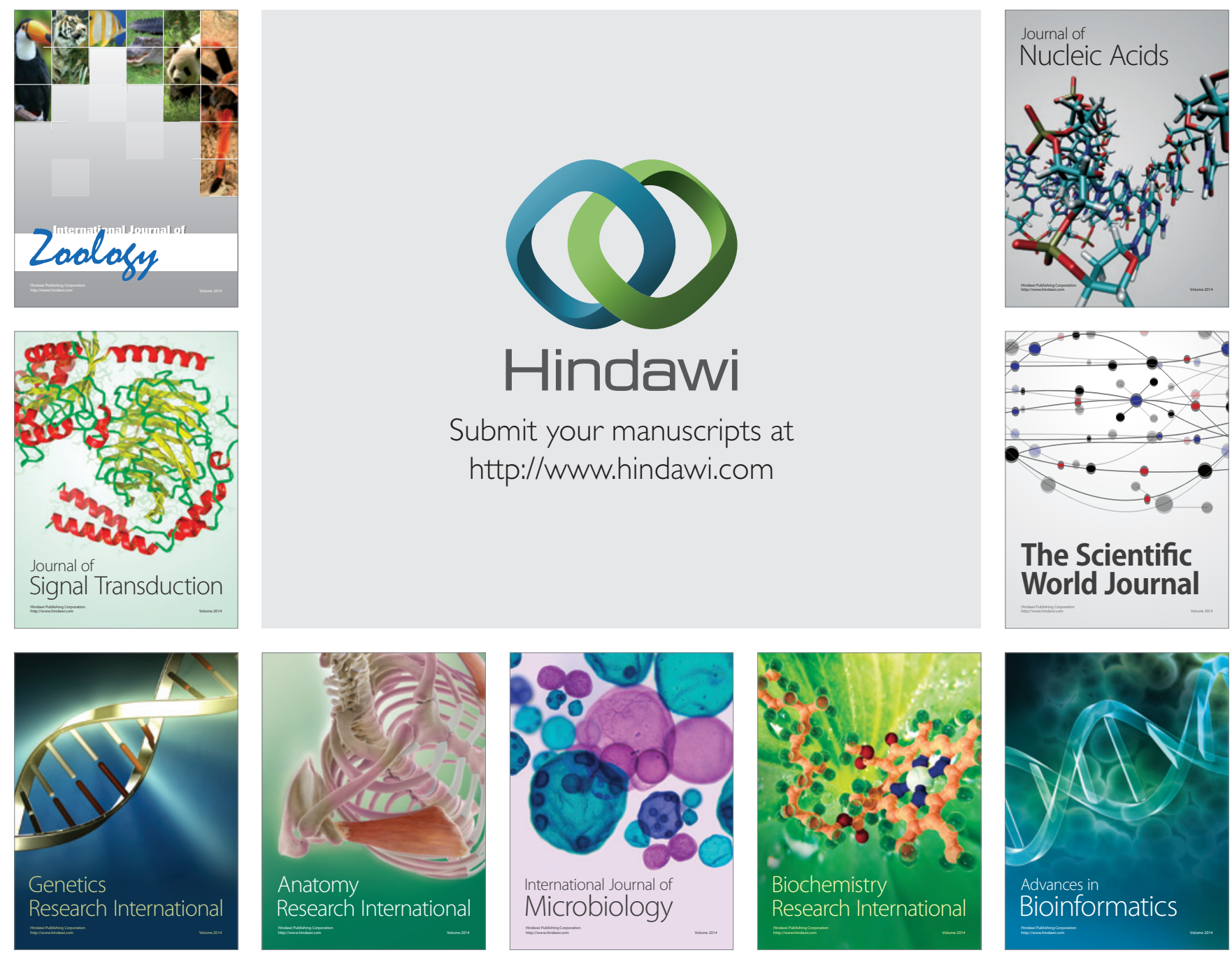

The Scientific World Journal
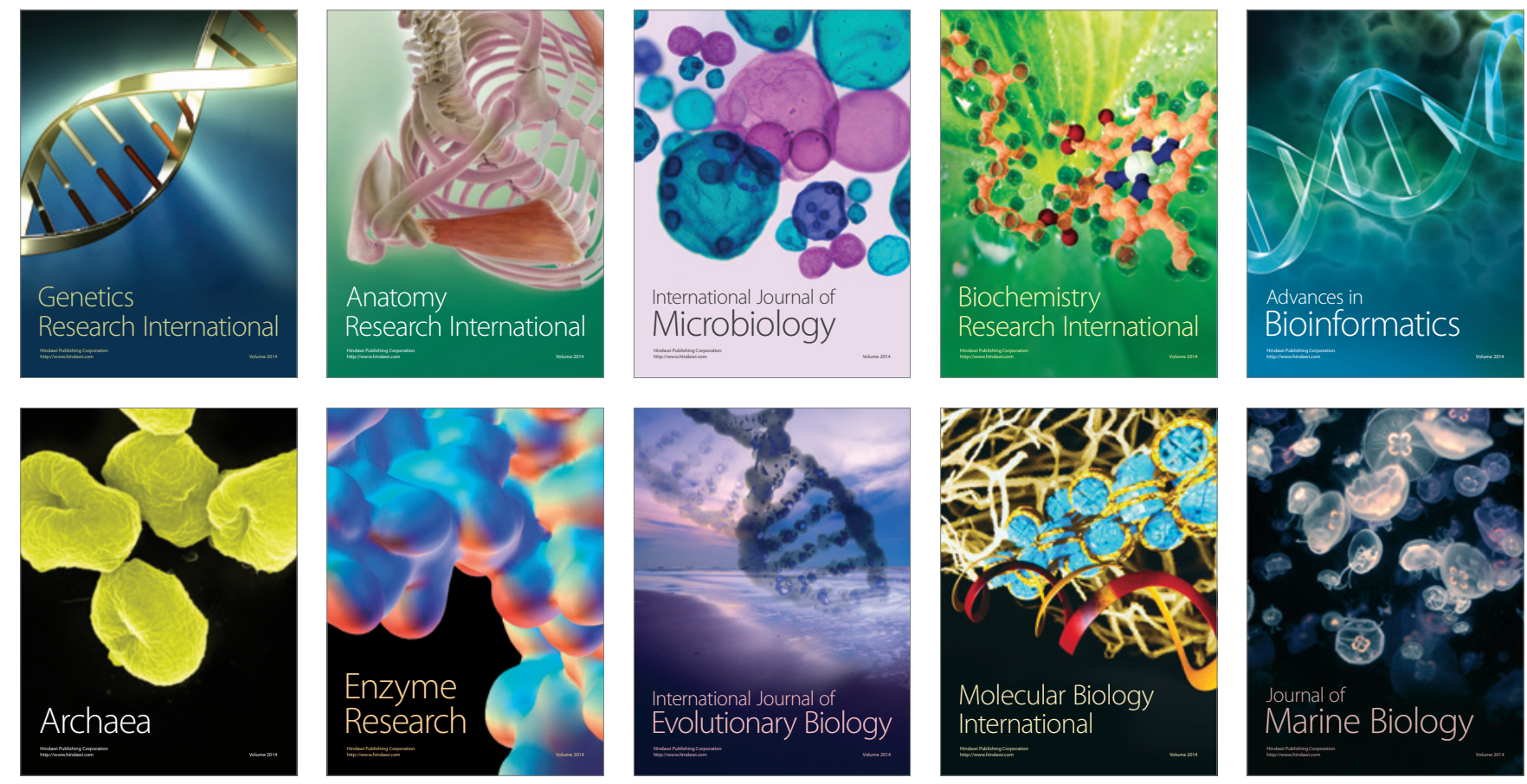